\title{
"Viajando" em Trinidad: um estudo do falar da ilha*
}

\section{Maria Jandyra Cavalcanti Cunha}

Professora da UnB. Pesquisadora Associada do

Programa de Pós-Graduaçãoem Comunicação da UnB. Doutorada em Lingüística, dentro da linha de pesquisa Língua no Contexto Social, pela Faculdade de Ciências Sociais, Universidade de Lancaster, Inglaterra (1996). Fez pós-doutorado em Lingüística Aplicada no Instituto de Estudos da Linguagem da Universidade Estadual de Campinas. Os temas de sua pesquisa são Identidade, migração e bilingüismo.

* Uma versão preliminar deste trabalho foi apresentada no / Congresso Internacional da ABRAPUI, realizado na Universidade Federal de Minas Gerais, em julho de 2007.

Resumo: O objetivo deste trabalho é apresentar algumas das estruturas do falar trinitino coletadas entre usuários de transporte público da ilha de Trinidad, Caribe, e, ao mesmo tempo, compará-las com estruturas produzidas na pidginização que sofre o inglês adquirido por brasileiros.

Palavras-chave: pidginização; crioulo; aquisição de segunda língua
Abstract: The aim of this work is to present some of the structures of the Trinidadian speech collected among users of public transport in the island of Trinidad, Caribbean, and, at the same time, to compare them to some of the structures produced in the pidginization of the English acquired by Brazilians.

Key-words: pidginization; creole; second language acquisition 



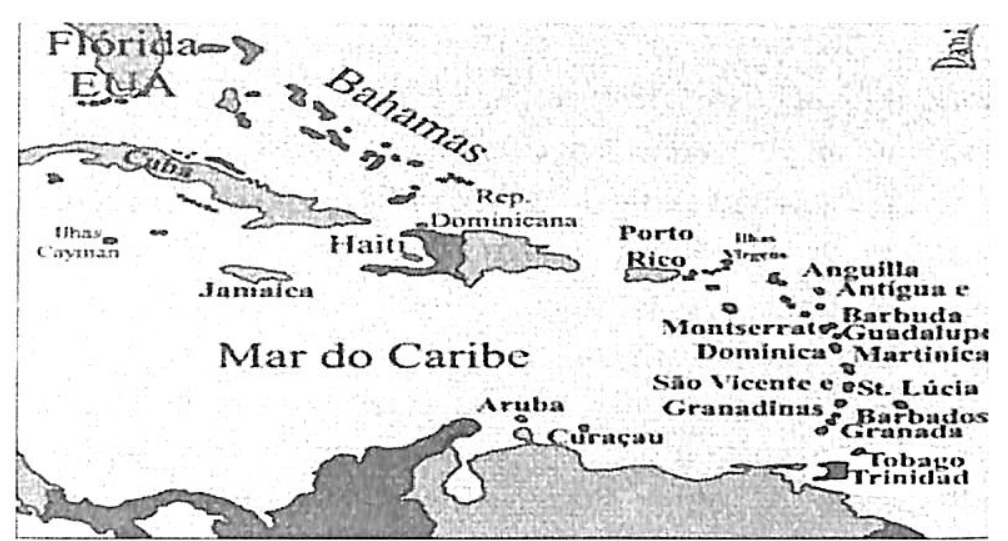

Figura 1: Localização geográfica de Trinidad e Tobago no Caribe ${ }^{1}$

\section{Introdução}

O título deste trabalho remete às inúmeras oportunidades que tive de usar o transporte público na ilha de Trinidad, na República de Trinidad e Tobago, onde trabalhei durante dois anos no campus da Universidade das Índias Ocidentais, The West Indies University (UWI) em St. Augustine ${ }^{2}$. Em Trinidad, o verbo inglês travel, viajar, tem outro significado que não o clássico 'ir a outros lugares, percorrer distâncias'. Nada a ver com o termo 'viagem', trip, alusivo ao estado provocado por drogas alucinógenas. To travel é 'compartilhar um veículo', o que, na prática, acaba sendo 'movimentar-se em transporte público'. À pergunta "How are you going to Port-ofSpain?" (Como você vai a Porto Espanha?), aprendi a responder "I am travelling", entendido como "Não vou de carro, vou de transporte público".

Em Trinidad, o transporte público pode ser o ônibus, o táxi coletivo ou a lotação. Os ônibus exibem carrocerias brasileiras, da Marco Pólo, de Caxias do Sul. Em determinados horários e trajetos, eles são do tipo 'frescão' carioca, com ar condicionado, uma conveniência para enfrentar o calor úmido do lugar. O que lá se chama por táxi é um automóvel de uso coletivo que transporta até cinco passageiros de pontos fixos a destinações variadas dentro de uma determinada zona. É diferente do
${ }^{1}$ Mapa extraído da revista $R B C C V(1: 22)$, jan./mar. 2007.

${ }^{2}$ A Universidade das Índias Ocidentais (UWI), fundada em 1948, tem três campi e sua sede é em Mona, na Jamaica. O terceiro campus é em Cave Hill, em Barbados. 
que conhecemos por táxi, ou 'carro de praça' ou 'carro de aluguel', que, embora também estacione em determinados pontos, faz um trajeto individualizado a critério do usuário. Em Trinidad, esse tipo de serviço não pode ser conseguido por um chamamento às ruas, deve ser contratado com antecedência e, à noite, jamais em cima da hora. Entretanto, o transporte público mais usado na ilha de Trinidad é, sem dúvida, o maxi-taxi. Na verdade o maxitaxié um tipo de lotação, uma perua que, por transportar até doze passageiros, é também reconhecida como vanpalavra já lexicografada em português (Houaiss, 2004) e originada de caravan, uma carruagem coberta por tecido nos tempos do faroeste.

Foi no maxi-taxique fiz muito de meu travelling pela ilha de Trinidad. É uma forma barata de atravessar a ilha do oeste para o leste, do norte para o sul, e viceversa. Seu percurso é indicado por uma faixa colorida pintada no exterior do veículo. Aqueles maxi-taxis que têm faixas de cores amarela, vermelha e verde saem do terminal central em South Quay em Porto Espanha, a capital do país. Os de faixa amarela percorrem os caminhos do lado oeste da ilha de Trinidad, inclusive aquele que leva a Chaguaramas, local do Parque Nacional. Os de faixa vermelha carregam os passageiros que vão para o leste da ilha, passando por St. Joseph (a primeira capital), Curepe, St. Augustine (onde fica o campus da UWI), Tunapuna (onde está localizado um dos mais importantes mercados públicos da zona centro-leste da ilha), Arima e Valencia, até a vila de Toco, já no nordeste da ilha. Os de cor verde seguem para duas das cidades mais populosas, San Fernando e Chaguanas (terra do Prêmio Nobel de Literatura, V. S. Naipul), além de Couva (vila-sede do WConnection, time de futebol onde jogam muitos brasileiros) e LaBrea (onde fica um dos maiores lagos de piche do mundo). De San Fernando saem os maxi-taxi de cor preta que conduzem os passageiros para o oeste, passando por Rio Claro (cidade de influência hispânica) até a costa atlântica da ilha, onde ficam as vilas balneárias de Mayaro e Manzanilla. Os de cor marrom chegam até 
Port Fortin, originalmente uma vila de pescadores que se tornou porto para o escoamento da produção da grande refinaria petrolífera Petrotin (ex-Shell, nacionalizada em meados dos anos setenta).

Passar por essas rotas (ver figura 2) é imergir na pluralidade etnocultural de Trinidad que, no maxi-taxi, é simbolizada não só pelo falar dos passageiros, mas, também, pela própria decoração do veículo. De fato, a decoração de um máxi-táxi é uma preciosa amostra do sincretismo cultural do povo de Trinidad. Nela convivem, em comunhão ecumênica, imagens de ícones religiosos como Jesus Cristo, Lord Hannamah e Buda. Afrontandose, lado a lado, penduram-se a figura sacra da Virgem Maria Sempre, sempre encoberta por véus, e as fotos profanas de mulheres vestidas por uma nudez sensual. No mesmo time do vale-tudo, jogam Brian Lara, o "Pelé do críquete trinitário", e dois ídolos do futebol internacional: o inglês David Beckham, o xodó das torcidas femininas, e seu excompanheiro no United Manchester, Dwight Yorke, o capitão do time trinitário na Copa da Alemanha de 2006 (Cunha, 2006). O ritmo da condução no máxi-táxi é tão frenético quanto alto é o som do soca, uma mistura de música soul com calipso, que retumba pelas janelas escancaradas na busca pela brisa marinha. Não tanto pelo gosto duvidoso, mas, sobretudo pelo intemperado manejo na direção, os motoristas dos máxi-táxi são muito criticados porque "ultrapassam, param, arrancam, cortam inadvertidamente e colocam em risco a vida de outros motoristas" (STEWART, 2001, p. 215). Realmente, o máxi-táxi pára a qualquer aceno às ruas e acaba convertendo-se em um desastre para outros motoristas, particularmente os forasteiros desavisados que vêm logo atrás, com um curto espaço de tempo para frear a cada parada súbita do veículo à frente. No entanto, da perspectiva do pedestre que geralmente caminha sob o sol escaldante do Caribe, o máxi-táxi é conveniente porque recolhe e desembarca passageiros em qualquer ponto do trajeto. 
${ }^{3}$ Este mapa simplificado, elaborado por Diego Cavalcanti Cunha, teve uma versão preliminar publicada em Cunha (2007a).

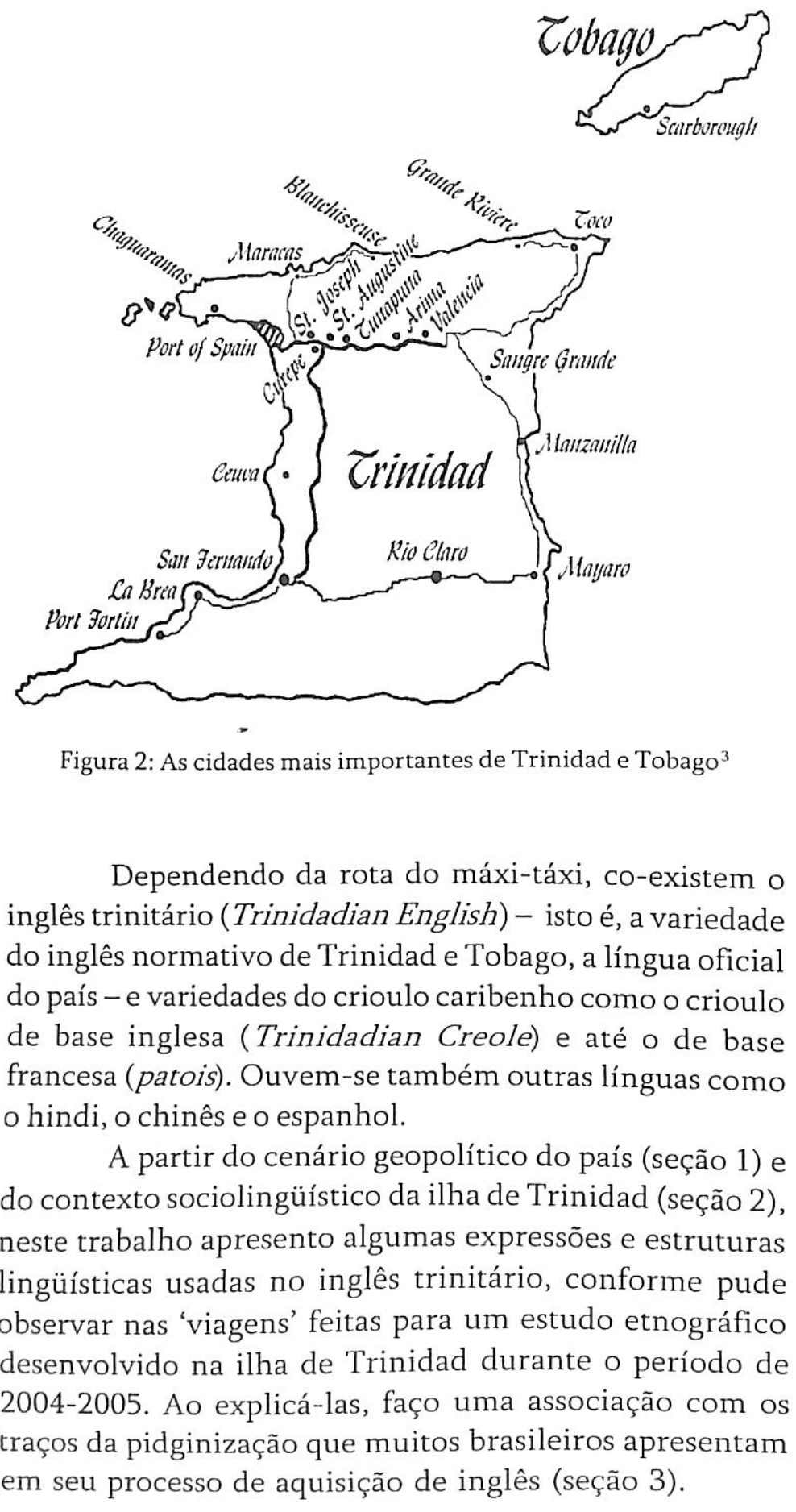




\section{Cenário geopolítico}

Como expliquei em trabalho anterior (CUNHA, 2007a), a República de Trinidad e Tobago, o país insular mais próximo do Brasil no mar do Caribe, é formada principalmente por duàs grandes ilhas, Trinidad $\left(4.828 \mathrm{~km}^{2}\right)$ e Tobago $\left(300 \mathrm{~km}^{2}\right)$, que juntas não atingem os 5.822,1 $\mathrm{km}^{2}$ do Distrito Federal brasileiro. Outras ilhas bem menores fazem parte dessa república-arquipélago, embora a maior parte dos mapas do Caribe não as inclua e, noutros, elas só possam ser vistas com uma lupa.

Antônio Houaiss (2001) ensina que quem nasce na República de Trinidad e Tobago é 'trinitário', 'trinitino' ou 'trinitário-tobaguense', sem distinguir a identificação daqueles que são especificamente da ilha de Trinidad. Uso como o adjetivo pátrio geral os termos 'trinitário' e 'trinitário-tobaguense' ou, com o mesmo sentido, um terceiro termo que transfiro da língua inglesa, Trinbagonian, como 'tribagoniano'. Trini, que no falar trinitário quer dizer 'trinitário', uso como opção nos adjetivos pátrios compostos, ex: 'trini-brasileiro' por 'trinitário-brasileiro'. Reservo trinitino apenas para os nascidos na ilha grande. O gentílico de Tobago é tobaguiano.

As ilhas de Trinidad e de Tobago estão afastadas uma da outra por 33 quilômetros, uma distância três vezes maior do que os 11 quilômetros que separam a ilha de Trinidad da costa da Venezuela, do outro lado do golfo de Paria (ver figura 1). Em termos geológicos, o país todo é uma extensão da América do Sul. Seu clima é marítimotropical com duas estações bem definidas: a seca, que vai de janeiro a maio, e a chuvosa, de junho a dezembro. Durante todo o ano, as temperaturas variam entre 25 e 33 graus centígrados.

Na ilha de Trinidad residem os 1,3 milhão habitantes do país, exceto por cerca de 50 mil que vivem na ilha de Tobago, onde a cidade mais importante, Scarborough, tem uma população de apenas $17 \mathrm{mil}$ habitantes. A capital da república, Port-of-Spain, Porto Espanha, tem cerca de 75 mil habitantes e está localizada na ilha maior (ver figura 2). Por ser o centro industrial e 
energético - com destaque para os robustos empreendimentos petrolíferos -, Trinidad é vista como o 'coração energético' do país, enquanto Tobago, que tem no turismo o seu forte por conta de suas praias paradisíacas, é considerada a 'alma serena' do país.

A história de Trinidad e Tobago é marcada por um entra-e-sai de estrangeiros desde o século XV. Cristóvão Colombo chegou às ilhas em 1498, mas elas só foram ocupadas pelos espanhóis no século XVII. Houve um fluxo grande de franceses que, com seus escravos falando patoá, se fixaram na ilha de Trinidad, que seria conquistada pelos ingleses em 1802, antes de Tobago que já havia sido regida por espanhóis, franceses, holandeses - ser cedida ao Reino Unido em 1814. As duas ilhas juntas passaram a constituir uma só colônia em 1889. A independência veio em 1962, quando Trinidad e Tobago passou a ser um país-membro da Comunidade Britânica, com a Rainha Elizabeth II como Chefe de Estado, representada por um Governador-Geral. Em 1976, os trinitários optaram pelo sistema republicano de Governo, mas permaneceram na Comunidade. Desde então, o chefe do Estado é o presidente da República, que é eleito por um colégio eleitoral. O Congresso é bicameral: a Câmara dos Representantes, com 36 membros eleitos pelo voto direto, e o Senado, com 31 membros indicados pelo presidente. O sistema judicial é espelhado no britânico, com cortes distritais e uma Suprema Corte. O presidente da Suprema Corte é apontado pelo presidente por sugestão do Primeiro Ministro e do líder da oposição. A Suprema Corte engloba a Corte Superior de Justiça e a Corte de Apelação. O tribunal de recursos de última instância é o Privy Council, em Londres.

Na ilha de Trinidad, concentra-se um dos dois maiores grupos étnicos do país, os indo-trinitários, que são ao todo $43 \%$ da população tribagoniana. O outro é formado pelos afro-trinitários, 39,59\% de habitantes em todo o país e $90 \%$ da ilha de Tobago. Os afro-trinitários descendem de escravos africanos, provenientes 
principalmente da África Ocidental, que foram trazidos como mão-de-obra para as plantações das colônias inglesas no Caribe e, depois de meio século de escravatura, esqueceram suas línguas e adulteraram suas religiões. Com a abolição, outros africanos - escravos libertados de navios estrangeiros e de outras partes do Caribe (entre outros, Barbados, São Vicente e Granada) - foram contratados como trabalhadores. Dependendo da história da colonização do lugar onde originalmente trabalhavam, esses novos africanos haviam entrado em contato com uma língua distinta, não só o inglês.

Também o grupo de indo-trinitários nunca foi homogêneo desde que, em meados do século XIX, os primeiros 225 indianos chegaram a Trinidad fugindo da miséria e da opressão política de Calcutá. Como novos trabalhadores, eles foram atraídos da Índia - à época outra colônia britânica - para substituir os africanos, depois da abolição da escravatura e já eram 144 mil, ao redor da segunda década do século XX. A grande maioria tinha sido aliciada na planície do rio Ganges, um número pequeno foi atraído em Bengala e em Punjab, enquanto outro grupo menor veio de Madras, no sul da Índia. A diferença entre eles não era somente geográfica, era também lingüístico-cultural.

O encontro entre africanos e indianos caracterizou um caso de população hospedeira versusgrupo imigrante, no qual os recém-chegados eram portadores de uma cultura estranha aos padrões locais. Os indianos não se inclinaram em favor da cultura local que se sentiu ameaçada porque os africanos, eles próprios, não haviam conseguido dar continuidade cultural à sua história. Até hoje as relações entre afro e indo-trinitários são difíceis e os dois grupos polarizam até no cenário político. Os afro-trinitários são a base eleitoral do Movimento Nacional do Povo (PNM/ People's National Movement), maldosamente apelidado de Pure Negro Men entre indo-trinitários, que são majoritariamente eleitores do Congresso Nacional Unido (UNC, United National Congress).

No meio dessa disputa étnica e política é o restante 
da população tribagoniana que faz o pêndulo balançar no "país arco-íris" - assim é chamado Trinidad e Tobago por causa da diversidade de seu povo. Mais de 15\% da população declara-se como mestiço (mixed). Outros grupos étnicos não especificados, junto com os síriolibaneses e os chineses formam 1,2\% da população. Os sírio-libaneses se mantiveram fechados entre si como um grupo à parte no oeste de Trinidad, enquanto os chineses espalharam-se em diferentes partes da ilha. $O$ poder e a supremacia econômica estão nas mãos da pequena população branco-européia, que está estimada em 0,6\% e concentrada nos bairros chiques de Porto Espanha.

Particularmente na ilha de Trinidad, a geografia humana fez nascer um pluralismo cultural, porém as relações raciais estão longe de serem exemplares naquele que se diz o "habitat mais heterogêneo do mundo". $\mathrm{Na}$ verdade, os trinitinos se misturam na escola e no trabalho, mas não no lazer. A interação é maior no topo da pirâmide social, onde a tez clara e o dinheiro farto permitem esquecer as cores e matizes pelas quais se identificam os trinitários. Tão racista quanto o uso de "preto" e "pardo" no Brasil, muitos trinitinos descrevem os indivíduos com expressões que, sofisticadamente faladas na língua francesa, aludem às cores do café, chocolate e leite - café noir (ou black, black coffee, em inglês), café-au-lait, chocolat, etc.

Desde meados do século passado, vários estudos de ciências sociais focalizaram a diversidade étnica e cultural de Trinidad e Tobago, tentando explicá-la de acordo com uma das três mais conhecidas teorias, que são: (1) a escola da "estratificação", que vê consenso nas normas e valores da sociedade apesar de sua diversificação; (2) a escola da "sociedade plural", que não enxerga consenso, mas grupos distintos mantendo, cada um, as suas próprias instituições sociais; e (3) a "sociedade de plantação", que afirma que as relações sociais trinitárias foram moldadas pela economia agrícola colonial e, desde então, mantiveram-se inalteradas. Entre 
os seguidores da primeira escola, estão Braithwaite (1954; 1975) e Nevadomsky (1982); na segunda está LaGuerre (1975; 1988); e na terceira, Best (1968). Entretanto, de acordo com o antropólogo Kevin Yelvington (1993), para quem nenhuma das três teorias dá conta da mudança social, uma análise da diversidade trinitária exigiria a transcendência a esses modelos e uma atenção especial às relações dos diferentes grupos étnicos através de estudos multidisciplinares, inclusive - acrescento estudos da linguagem.

\section{Contexto sociolingüístico}

O inglês trinitário é a língua oficial de Trinidad e Tobago, usada em repartições públicas, escolas e meios de comunicação. O hindi - assim identificado localmente o bhojpuri, uma língua do norte da Índia - é falado entre indo-trinitários e muito usado na música popular, como o chutney e a soca. O árabe e o chinês são falados nas comunidades transplantadas de sírio-libaneses e de chineses, que mantêm suas línguas e tradições como parte da identidade social. Na televisão aberta, há um canal com a programação em árabe e dois com a programação em hindi.

O espanhol vem sendo alçado à categoria de segunda língua do país, desde que, durante as negociações da Associação de Livre Comércio das Américas (ALCA), a cidade de Porto Espanha se candidatou para sede. Ao lado do inglês, o espanhol passou a constar na documentação oficial do Estado e nas placas e indicações de nomes nas ruas da capital. A partir de 2003, a língua espanhola começou a ser incluída no currículo obrigatório de escolas básica e média e, por decreto, deverá ter seu ensino assegurado em todo o país a partir de 2010. A pesquisa de Luengo e Moodie-Kublalsingh (2004) sobre a aprendizagem de espanhol em escolas trinitárias é uma amostra desse esforço.

O crioulo é amplamente falado no restante da ilha. O "crioulo" desenvolve-se a partir do "pidgin", uma língua 
${ }^{4}$ Em Cunha (2007b), incluo "pidgin" e "crioulo", na terminologia básica a ser dominada pelo pesquisador da linguagem. Sobre pidgin e línguas crioulas, ver Couto (1996). auxiliar que surge do contato estreito de línguas distintas, geralmente de povos com assimetria na condição política e econômica, um exercendo superioridade sobre o outro. Quando o pidgin falado por uma geração começa a ser passado a gerações seguintes, seu status muda e ele é então reconhecido como um crioulo. Tornando-se mais desenvolvido lexical e gramaticalmente, o crioulo pode se tornar a língua nativa de uma comunidade de fala ${ }^{4}$. Este é o caso em Trinidad e Tobago.

Em diferentes pontos do Caribe, o crioulo se desenvolveu como variedades que se distinguem na pronúncia e entonação, embora apresentem, entre si, semelhanças na sintaxe. O crioulo falado em Tobago assemelha-se ao crioulo da Jamaica porque, apesar da distância entre as ilhas de Trinidad e Tobago ser menor do que os 1,6 mil quilômetros que separam Tobago da Jamaica, estas têm grande proximidade étnica: nos dois lugares, a população de origem africana é majoritária. O crioulo de base inglesa na ilha de Trinidad se distingue do falado em Tobago e na Jamaica por conta da múltipla influência etnocultural de imigrantes. O crioulo trinitino também é fruto do contato entre a língua inglesa e línguas africanas, principalmente as faladas na África Ocidental (de onde vinham os escravos) como tui e ioruba, mas também do espanhol, francês e hindi. Por isso, embora tenha como base o inglês, o crioulo trinitino apresenta muitos vocábulos e expressões originárias de outras línguas que não a inglesa ou as africanas e que, em Trinidad, podem ter significações próprias, por exemplo: fête (contato com francês) significando "festa" (substantivo) e "festejar"(verbo); cote ci, cote la (também contato com francês) "um pouco aqui, um pouco lá"; "meio-a-meio"; dougla (contato com hindi, dogala) um novo fenótipo: a mistura entre africano e indiano; parang (contato com espanhol da Venezuela, paranda), canções natalinas, seresta.

Internamente, o crioulo de base inglesa se estende em um contínuo lingüístico que vai do acroleto, uma variedade mais próxima do Standard English, até o basileto, bem mais distante do inglês normativo (SOLOMON, 1993). 
Ao chegar à ilha de Trinidad, o não-nativo de língua inglesa se confunde, quando tenta interagir com as pessoas do lugar. Freqüentemente, o que ele ouve é o crioulo, e não o inglês normativo que aprendeu nos bancos de escola. Inseguro, o visitante passa a acreditar que não sabe falar a língua inglesa, porém, aos poucos ele aprende que o inglês e o crioulo co-existem. Muitos falantes do crioulo são capazes de alterar o código de fala para o inglês e o inverso acontece com falantes de inglês, que usam o crioulo para entrar em entendimento com interlocutores que sejam monolíngües. No dia-a-dia, o Trinidadian English acaba incorporando muitas expressões do crioulo. Com o tempo, o próprio visitante aprende a usar algumas expressões e estruturas que voltam do crioulo para melhor participar na comunidade hospedeira, nem que seja apenas para pechinchar no mercado em Tunapuna.

Em lugares mais isolados no norte da ilha de Trinidad, fala-se o patois, um crioulo de base francesa que, em outros tempos, foi muito falado em Trinidad e também na costa venezuelana de Paria. Essa herança de quase cem anos de história, pode ser ouvida nas cercanias de Blanchisseuse e Grand Riviere. Em Cunha (2007), cito Blanchisseuse e Maracas como praias paradisíacas da orla do Mar do Caribe, identificando a primeira como mais isolada e a segunda como bastante freqüentada. É justamente o isolamento de Blanchisseuse, causado pela dificuldade de acesso em estradas mal cuidadas, que ajuda na manutenção do patoá. Embora a vila de Grand Riviere seja um centro de ecoturismo muito procurado por turistas que querem observar a desova de tartarugas gigantes e fazer trilhas na vizinha floresta tropical, ela também é de difícil acesso, o que favorece a manutenção do patoá.

O inglês trinitário também fez incorporar ao Standard English muitos de seus vocábulos e expressões as expressões do inglês trinitário, exemplo: to lime. O verbo to lime descreve a ação de estar à brisa em estado de letargia. É interessante observar que os falantes nativos do inglês que vêem do mundo anglo-saxão - onde a máxima "tempo é dinheiro" é o que vale - desconhecem o verbo 
to lime e, quiçá, a ação de se estar sem fazer nada, à brisa. No Brasil, "to lime" seria "estar à toa" e, no Rio Grande do Sul, a expressão "lagartear" poderia ser uma boa tradução se fosse considerado "o estar ao sol", em vez de "à brisa", pois é quando o sol sai que, nos dias muito frios, os gaúchos querem se aquecer ao sol, como os lagartos.

Por sua vez, o inglês trinitário - que antigamente se baseava no inglês vindo da Inglaterra - adotou agora muitos vocábulos usados nos Estados Unidos, país que é hoje o maior parceiro comercial de Trinidad e Tobago. Os "americanismos" incluem: hood por bonnet, capô de carro; apartment por flat, apartamento; truck por lorry, caminhão; two weeks'time por a fortnight.

\section{Pidginização do inglês}

No processo de aquisição do inglês, muitos brasileiros falantes de português fazem surgir um pidgin, no contato de sua língua materna com a língua-alvo.

A hipótese da pidginização foi formulada por Schumann (1978), em seus estudos sobre aculturação, nos quais ele caracterizou os estágios iniciais de aquisição de segunda língua pelos mesmos processos responsáveis pela formação do pidgin. Schumann também afirmou que, dependendo do grau de distanciamento social e psicológico entre o falante e a cultura da língua-alvo, a pidginização persiste e o falante fossiliza $\circ$ processo de desenvolvimento da língua-alvo. De acordo com Bickerton (1977), a pidginização acontece nos estágios primitivos da aquisição de uma segunda língua (L2), quando ainda há um insumo limitado da língua-alvo. A pidginização é marcada pela relexificação de algumas palavras-chaves na língua-alvo que também são refonologizadas com o substrato do sistema fonológico da língua materna.

Analisando algumas estruturas do crioulo de base inglesa falado em Trinidad, percebe-se que um processo de pidginização semelhante ao que formou o crioulo caribenho ocorre na aquisição do inglês adquirido por alguns brasileiros. Compare as expressões a seguir: 
- Good day!

O cumprimento matinal do trinitário não é "Good morning!" como no Standard English. O trinitário usa dizer "Good day!", o que corresponderia à expressão francesa "Bon Jour!", com que teve contato. Para o brasileiro, vale a associação já que também dizemos "Bom dia!" pela manhã.

\section{- Good night!}

Assim como "Good day!", "Good night" ("Boa noite", em inglês) é um cumprimento usado tanto na chegada como na saída. Os trinitários não fazem a clássica diferença entre "Good evening" e "Good night", exigida pelo Standard English. Semelhantemente, na pidginização do inglês que está sendo adquirido por brasileiros também não há essa diferença que, aliás, é inexistente em português.

\section{- It making hot.}

Trinitários dizem "It making hot", em uma expressão similar ao "Il fait chaut" do francês. Brasileiros também usam a mesma expressão, ainda que eles acrescentem o verbo auxiliar: "It's making hot", correspondendo a "Está fazendo calor".

\section{- It have ... (no sentido de existir).}

No falar trinitário, a noção de existência contida em There is/are é substituída por "It have", correspondendo a "Il y a" do francês, como em "It have three cow in the yard". Importante notar aqui que o substantivo "cow" aparece no singular, mesmo acompanhado do numeral "three", três. A mesma estrutura surge na pidginização do inglês por brasileiros que usam o verbo "ter" no sentido de "existir", em português. Em relação à não pluralização do substantivo em inglês, muitas vezes, ela também é inexistente no português oral, geralmente entre pessoas menos letradas, "Têm três vaca no quintal". 
- He has thirty years

Em Standard English, expressa-se a idade com o verbo "be", ser, como em: "He is three years old". No trinitário, expressa-se com o verbo "have", ter, "He has thirty years", correspondendo ao francês "Il a trente ans". Para os brasileiros, a interferência vem de estrutura semelhante com o verbo ter, "Ele tem trinta anos".

- Yes! Is a (Trini) t’ing!

Nessa expressão, que significa literalmente "Sim! É uma coisa trinitária!”, não há a presença normativa do pronome pessoal (subjective pronoun). Observa-se também que o fonema th de thing/q i h/, é escrito como é pronunciado pelos trinitinos: $/ \mathrm{t} \mathrm{i} \mathrm{h/.} \mathrm{O} \mathrm{inglês} \mathrm{pidginizado}$ de brasileiros pode apresentar a mesma ausência do pronome. A dificuldade na pronúncia também é uma realidade para o falante brasileiro, que não está acostumado com a fricativa dental /q/.

\section{- Yes/no questions}

No falar trinitário, a pergunta que demanda respostas "sim/não" é marcada por um contorno de entonação terminal, exemplo: "He have children [entonação ascendente]". Não se marca a diferença do enunciado afirmativo com a inversão da ordem das palavras ou introdução de auxiliares, como no inglês normativo: "Has he any children?" ou "Does he have any children?". Como no português, a entonação é ascendente nas perguntas, na pidginização do inglês por brasileiros é comum a mesma estrutura apresentada no falar trinitário.

\section{- Perguntas sobre o lugar}

Há substituição do pronome interrogativo nas perguntas para formular pedidos de informação de lugar, usando-se em vez de "where" a expressão "which part", como em: "Which part you living", por "Where do you live?", uma estrutura que evoca o "Em que parte você mora?", que aparece na pidginização do inglês por brasileiros. 


\section{Considerações finais}

Preocupada com a ausência de outros contextos de fala inglesa que não os da Austrália, Estados Unidos e Reino Unido, nas aulas de inglês como língua estrangeira nas escolas brasileiras, neste artigo apresentei um novo panorama sociolingüístico: Trinidad e Tobago.

O inglês, língua oficial de Trinidad e Tobago, é, no coloquialismo do dia-a-dia, contaminado pelo crioulo, que traz em sua descrição lingüística as camadas históricas da movimentação de migrantes no país. Com influência do francês, do patois e também do espanhol, esse Trinidadian English precisa ser entendido para que o indivíduo consiga extrair o máximo da sociedade local.

A partir de minha observação in loco, listei algumas estruturas desse falar trinitário semelhantes àquelas geradas por brasileiros como resultado do esforço de produção do inglês como língua-alvo. Essa observação poderá servir como ponto de partida para uma investigação futura da pidginização, nas primeiras fases de aquisição do inglês por falantes brasileiros. 


\section{Referências}

BEST, Lloyd. Outline of a model of pure plantation economy. Social and economic studies, vol. 17, n. 3, 1968. p. 283-326.

BICKERTON, Derek. Pidginization and creolization: language acquisition and language universals. In: Albert Valdman (org.). Pidgin and creole linguistics, Indiana U.P., 1977. p. 49-69. . The problem of cultural integration in Trinidad. In.: Social and economic studies, vol. 3, n. 1, 1954. p. 82-96.

Social stratification and cultural pluralism. Mona: Institute of Social and Economic Research, University of The West Indies, 1975 (1954).

COUTO, Hildo. Introdução ao estudo das línguas crioulas e pidgins. Brasília: Editora da Universidade de Brasília, 1996.

CUNHA, Maria Jandyra. Um país revelado pela bola. Blog do Noblat, Estadão. Disponível em http://noblat1.estadao.com.br . Acesso: 10 de junho de 2006.

Língua e identidade em vidas migrantes. In.: CUNHA, M. J., GURAN, Milton et al. Migração e identidade: olhares sobre o tema. São Paulo: Centauro, 2007a. p. 133- 190.

. O português para falantes de outras línguas: redefinindo tipos e conceitos. In.: ALMEIDA FILHO, José Carlos P.; CUNHA, M. Jandyra C. Projetos iniciais em português para falantes de outras línguas. Campinas-SP: Pontes/Brasília: EDUMB (co-edição), 2007b. p. 13-31.

HOUAIS, Antônio. Dicionário Houaiss da língua portuguesa. Rio de Janeiro: Objetiva, 2004.

YELVINGTON, Kevin (org.). Trinidadethnicity (Warwick University Caribbean Studies). Londres: Mcmillan Caribbean, 1993. LA GUERRE, John Gaffar. Afro-Indian relations in Trinidad: an assessment. Social and economic studies, vol. 3, n. 3, 1975. p. 291-306.

Race relations in Trinidad and Tobago. In: RYAN, Selwyn (org.). Trinidad and Tobago: the independence experience 19621987. St. Augustine: Institute of Social and Economic Research, University of The West Indies, 1988. p. 193-206. 
LUENGO, Esperanza; MOODIE-KUBLALSINGH, Sylvia.

Cantamos en Español CLLNews, n. 4, Nov. - Dez. 2004. p. 17-

21 (Disponível em: http://www.uwi.edu/fhe/cll/news).

MENDES, John. Cote ci, cote la. Trinidad \& Tobago dictionary. Newtown. T\&T: Mediante, 2003.

NEVADOMSKY, Joseph. Social change and the East Indians in rural Trinidad: a critique methodology. Social and economic studies, vol. 31, n. 1, 1982. p. 90-126.

SOLOMON, Denis. The speech of Trinidad. A reference grammar. Caribbean Issues, School of Continuing Studies, Trinidad, 1993.

STEWART, John O. The old men used to dance. In: BROWN, Stewart; WICKHAM, John (orgs.). Caribbean short stories. Oxford: Oxford University Press, 1991. p. 215-219. 